\title{
Teresa López-Fellisa y Silvia G. Kurlat (Eds.). Historia de la ciencia ficción latinoamerica. Madrid/ Frankfurt am Main: Iberoamericana/ Vervuert, 2020, 507 páginas
}

María Carpio-Manickam

Carpio-Manickam, M. (2022). Teresa López-Fellisa y Silvia G. Kurlat (Eds.). Historia de la ciencia ficción latinoamerica. Madrid/ Frankfurt am Main: Iberoamericana/ Vervuert, 2020, 507 páginas. Revista de Filología y Lingüística de la Universidad de Costa Rica, 48(1), e48516. doi: https://doi.org/10.15517/rfl.v48i1.48516

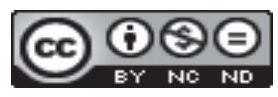

Doi: https://doi.org/10.15517/rfl.v48i1.48516

URL: https://revistas.ucr.ac.cr/index.php/filyling/index 
Revista de Filología y Lingüística de la Universidad de Costa Rica

ISSN: 0377-628X

ISSN: 2215-2628

filyling@gmail.com

Universidad de Costa Rica

Costa Rica

\section{Teresa López-Fellisa y Silvia G. Kurlat (Eds.). Historia de la ciencia ficción latinoamerica. Madrid/ Frankfurt am Main: Iberoamericana/ Vervuert, 2020, 507 páginas}

Carpio-Manickam, María

Teresa López-Fellisa y Silvia G. Kurlat (Eds.). Historia de la ciencia ficción latinoamerica. Madrid/ Frankfurt am Main: Iberoamericana/ Vervuert, 2020, 507 páginas

Revista de Filología y Lingüística de la Universidad de Costa Rica, vol. 48, núm. 1, e48516, 2022 Universidad de Costa Rica, Costa Rica

Disponible en: https://www.redalyc.org/articulo.oa?id=33268016012

DOI: https://doi.org/10.15517/rfl.v48i1.48516

\section{(c) (1) $\Theta$}

Esta obra está bajo una Licencia Creative Commons Atribución-NoComercial-SinDerivar 3.0 Internacional. 


\section{Teresa López-Fellisa y Silvia G. Kurlat (Eds.). Historia de la ciencia ficción latinoamerica. Madrid/ Frankfurt am Main: Iberoamericana/ Vervuert, 2020, 507 páginas}

Maria Carpio-Manickam

University of North Texas, Denton, Texas, Estados Unidos

Maria.Carpio@unt.edu

(D) https://orcid.org/0000-0002-1903-2593
DOI: https://doi.org/10.15517/rfl.v48i1.48516

Redalyc: https://www.redalyc.org/articulo.oa? $\mathrm{id}=33268016012$

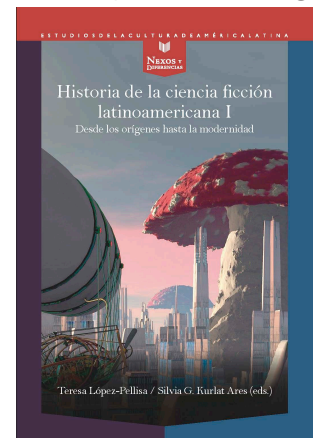

López-Fellisa Teresa, G. Kurlat Silvia. Historia de la ciencia ficción latinoamerica. 2020. Madrid/ Frankfurt am Main. Iberoamericana/ Vervuert. 507pp.

Historia de la ciencia ficción latinoamericana I. Desde los orígenes hasta la modernidad es una colección de quince ensayos en los cuales se documenta la contribución de los escritores latinoamericanos a la ciencia ficción (CF) entre los siglos XVIII y principios del XX. Las aproximaciones a los textos de CF dejan entrever algunas similitudes y diferencias en las temáticas abordadas. Cada ensayo provee el contexto social, político y cultural de que se alimenta cada texto, los cuales fueron publicados en diferentes modalidades: diarios, revistas, folletines, cartas, novelas y cuentos. Asimismo, se enfatiza la influencia de los pioneros extranjeros de la CF más reconocidos del siglo XIX: Julio Verne, H. G. Wells y Edgar Allan Poe. La mayoría de la producción latinoamericana de los primeros escritores se mantuvo distante de las teorías científicas de la evolución y la relatividad en boga durante el siglo diecinueve. Con excepción de México, los autores se enfocaban en las temáticas del ocultismo, el espiritismo y el uso de la tecnología que otorga a sus protagonistas poderes especiales, aunque alejadas de las teorías científicas de la evolución y la relatividad en boga durante el siglo diecinueve. Esta vista panorámica de la CF latinoamericana conforma una base de datos invaluable para los estudiosos actuales y futuros de un género literario que en el pasado fue visto por la crítica literaria como literatura de quiosco pero que lentamente ha forjado una presencia entre el público lector que resulta ya innegable.

En el primer ensayo de la colección, "La ciencia ficción en América Central (1896-1951)”, Iván Molina Jiménez estudia el caso de los países centroamericanos. Hasta la actualidad, Guatemala, Costa Rica y Nicaragua son los únicos en contribuir a la CF. Estas eran contribuciones esporádicas de escritores que tenían poco conocimiento científico y tecnológico. Más bien, escribían influenciados por los autores de la CF más reconocidos del siglo XIX previamente mencionados. Los autores centroamericanos enfatizan el futurismo, más que la tecnología y la ciencia y descuellan la temática antiimperialista que más tarde en los albores del siglo veinte serían bien conocidos en Ariel de Enrique Rodó. Molina Jiménez asegura que hay una palpable ausencia de la incursión de las mujeres en este género literario dominado por los varones desde sus inicios en Estados Unidos y Europa. 
Contrario a los centroamericanos, Argentina cuenta con autores ya reconocidos en el ambiente literario que también se interesaron en la CF, tales como Domingo Faustino Sarmiento, Horacio Quiroga, Juana Manuela Gorriti, Leopoldo Lugones, Adolfo Bio Casares y Jorge Luis Borges, asunto que se analiza en los ensayos "Sombras tras la lámpara de gas: la temprana ciencia ficción argentina (1816-1930)" de Soledad Quereilhac y "Los años invisibles: ciencia ficción argentina (1930-1979)" de Silvia G. Kurlat Ares. Entre las temáticas más sobresalientes de la CF argentina temprana, señala Quereilhac, sobresalen las utopías futuristas, los viajes interplanetarios, los autómatas, los humanos artificiales, la experimentación. Al igual que otros países latinoamericanos, algunos relatos argentinos del siglo XIX se asientan en el marco del espiritismo y el ocultismo, tendencias de la narrativa de esa época. Kurlat por su parte se enfoca en las publicaciones de la segunda mitad del siglo veinte influenciadas por la dictadura y el recelo de los autores canónicos quienes continuaban considerando el género como objeto de consumo de las clases bajas. A pesar de esto, recalca Kurlat, la CF argentina logra adquirir un nombre.

En "Ciencia ficción boliviana (1864-1967)", Giovanna Rivero asegura que la CF de este país se inicia a finales del siglo XIX. Para apoyar su argumento alude a la novela La isla (1864) de Manuel Maria Caballero. Curiosamente, Rivero contradice sus observaciones al afirmar más adelante que esta novela no es considerada propiamente de CF y que la primera novela de CF boliviana fue Kori-Marka (1936) de Julio Aquiles Munguía Escalante. Por los resúmenes que Rivero ofrece de cada obra, se puede asumir que la primera es de corte fantástico, mientras que la última tiene más características de CF (una ciudad futurista poblada por tráfico aéreo y tranvías verticales que viajan a gran velocidad). Lo más interesante de la CF boliviana es su apego a los espacios naturales, los personajes indígenas, las leyendas y los mitos andinos, asunto que la diferencia de la CF de otros países latinoamericanos.

En "Otras ciudades, otro Chile: ciencia ficción chilena desde la modernización hasta el golpe del 73 (1877-1973)", Macarena Areco Morales analiza las contribuciones de los autores chilenos a la CF latinoamericana. A diferencia de la CF boliviana, el primer relato de CF chileno, Desde júpiter (1877) de Francisco Miralles, despliega las características de una obra de CF: el avance científico de los habitantes en otros planetas quienes desde su espacio analizan el comportamiento de los humanos. Las ciudades futuristas y utópicas, típicas de la CF de otros países latinoamericanos, es también una característica de la CF chilena fundacional. Este enfoque, sin embargo, se vuelca hacia la distopía en las obras de la segunda mitad del siglo veinte. En estas se recrea el imperialismo estadounidense como una amenaza para la sociedad chilena. Otras temáticas distópicas importantes de la producción chilena orbitan alrededor de los peligros y los avances de la ciencia y la tecnología, los viajes espaciales.

La CF en Colombia, asegura Campo Ricardo Burgos López en su ensayo "Los comienzos de la ciencia ficción en Colombia (1876-1936)", emerge cuando la nación intenta dejar atrás la época conservadora (finales del siglo XIX). Burgos López apunta dos etapas de la CF colombiana: la conservadora (1876-1930) y la liberal (1930-1946). En la época conservadora los textos de CF son escasos y tratan de abrirse lugar entre las tendencias literarias de la época: el realismo marcado por el nacionalismo. Las obras pioneras de finales del siglo XIX tratan los motivos de la máquina, los eventos misteriosos de corte espiritista y la existencia de la vida en otros planetas. Asimismo, en algunas obras sobresale la visualización sobre Bogotá en el siglo XXI. También es digno de mencionar la contribución de las escritoras a este género y su visión de la mujer colombiana del siglo veintiuno la cual se aparta del espacio doméstico y se envuelve exitosamente en las esferas públicas de la política y las universidades. Con todo, interesantemente Burgos López concluye que, a pesar de los intentos de crear CF, los autores y autoras colombianas no lograron su objetivo.

En "México de los recuerdos: la ciencia ficción mexicana desde los orígenes hasta 1960", Miguel Ángel Fernández Delgado señala que la CF mexicana tiene inicios más tempranos en comparación con los otros países latinoamericanos. Los primeros asomos se remontan a la segunda mitad del siglo XVII y el XVIII. Dichos manuscritos no seguían la fórmula de la CF, más bien, y ante la amenaza de la inquisición, se enfocaban en asuntos religiosos y espirituales, principalmente los raptos. De acuerdo con Férnandez Delgado, los temas 
relacionados con la política son los más sobresalientes en el siglo XVIII y XIX, especialmente sobresalen las ciudades utópicas con énfasis en la igualdad social y económica. La influencia francesa y el pensamiento positivista de finales del siglo XIX y principios del XX, darían forma a las obras de CF de la época cuyos temas técnico- científicos seguían el modelo de Julio Verne (submarinos y espacios acuáticos). Las perspectivas científicas se tornarían hacia una visión humanista durante las primeras décadas del siglo veinte. Las obras de autores de diversas áreas geográficas del país (Zacatecas, Coahuila, Chihuahua), por ejemplo, enfatizaban la educación como la clave para el progreso de la sociedad mexicana. Tampoco faltarían las aportaciones a la CF de autores canónicos tales como Amado Nervo, Martín Luis Guzmán, Francisco L. Urquizo, José Vasconcelos, Rafael Bernal, Carlos Fuentes, Juan José Arreola y Octavio Paz. Curiosamente, Fernández Delgado se enfoca en las aportaciones a la CF de los varones, haciendo mención a apenas dos escritoras: Guadalupe Dueñas y Nahui Olin; asunto que no sorprende pues es la tendencia de algunos críticos a dejar fuera las aportaciones femeninas, siendo este el caso en la mayoría de los ensayos de este volumen.

Estos son solamente algunos ejemplos de la CF latinoamericana desde sus inicios en el siglo diecinueve hasta mediados del siglo veinte. No cabe duda de que Historia de la ciencia ficción latinoamericana I. Desde los origenes hasta la modernidad es una valiosa contribución al campo de estudios de la CF global ya que no solamente aborda las diferentes circunstancias sociales, políticas y culturales que dieron forma a la CF de los países latinoamericanos, sino expone cómo los autores se apropiaron de un género literario extranjero y lo amoldaron a espacios y temáticas locales a pesar de la poca popularidad de la que gozara el género hasta la primera mitad del siglo veinte. 